\title{
Contentious ethical issues in community genetics: let's talk about them
}

\author{
Jörg Schmidtke ${ }^{1}$. Martina C. Cornel ${ }^{2}$
}

Published online: 12 December 2019

(C) Springer-Verlag GmbH Germany, part of Springer Nature 2019

"Community genetics is the art and science of the responsible and realistic application of health and disease-related genetics and genomics knowledge and technologies in human populations and communities to the benefit of individuals therein. Community genetics is multi-, inter- and transdisciplinary and aims to maximize benefits while minimizing the risk of harm, respecting the autonomy of individuals and ensuring equity." (Ten Kate et al. 2010).

In the light of this definition, any disrespect for the autonomy of individuals is morally questionable. However, autonomy of the individual cannot be absolute. Individual rights and duties always need to be balanced with those of the community, and there is considerable cultural variability as to where to draw the lines. As Editors of this Journal, although personally rooted in the cultural tradition of the "Western individualism", we feel obliged to accept this variability and understand the Journal also as a forum for discussing ethical diversity. We neither wish to exert any kind of "ethical imperialism" nor do we want to promote unreflected "ethical relativism". Doing so, we must accept walking on "thin ice" at times.

"Economic gains or eugenic aims are not the goal of community genetics." (Ten Kate et al. 2010). Two recent papers in this Journal have touched these central issues (Sinha et al. 2019; Singer et al. 2019). It was our decision to accept these

Jörg Schmidtke

Schmidtke.joerg@mh-hannover.de

Martina C. Cornel

mc.cornel@amsterdamumc.nl

1 Hannover Medical School, Institute of Human Genetics, Carl-Neuberg-Str. 1, D-30623 Hannover, Germany

2 Amsterdam UMC, Vrije Universiteit Amsterdam, Clinical Genetics, Section Community Genetics, Amsterdam Public Health Research Institute, De Boelelaan, 1117 Amsterdam, The Netherlands papers and have them accompanied by invited editorials (Modell 2019; Bittles 2019).

The article "Haemoglobinopathies in India: estimates of blood requirements and treatment costs for the decade 20172026" by Sinha et al. stated: "To avert a public health crisis there is an urgent need to fully implement the prevention programme for haemoglobinopathies", which would include carrier screening programmes. Is such an argument in conflict with the statements in the paper of ten Kate et al.? We believe that there is no clear yes or no as an answer to this question. When the goal of a carrier screening programme is to enable couples to make an informed reproductive choice, the consequence will often be a reduced prevalence, but this interpretation of goal and consequence is not shared by all. Also in genetic counselling decades ago there was discussion about the goal of genetic services: prevention vs. helping clients to make their own informed decisions (Biesecker 2001). They noted discrepancies in whether the goals to prevent had a societal intent or were individualized. In fact, prevention programmes aiming at reducing the birth prevalence of genetic diseases have often been underpinned by economic arguments. Resource allocation in medicine always bears ethical dilemmas including direct or indirect exertion on individuals, and publicly funded carrier screening programmes are no exception (Schmidtke 1998; De Wert et al. 2012; Rogowski et al. 2014). Different societies will differ in the presence of directive elements contained in such programmes, and in the possibilities of people to react to them.

The article "Consanguinity and Genetic Diseases Among the Bedouin Population in the Negev" by Singer et al. contains several contentious issues, some of which were addressed in the Editorial by Alan Bittles (2019). One particular aspect here is reproductive choice in a society with a tradition of strict obedience to marriage rules in favour of consanguineous mating leading to high rates of infant mortality and accumulation of recessive diseases in this population. The authors suggest implementing genetic counselling and "medical approval" prior to marriage as measures of intervention in specific tribes. 
This could be (mis)understood as replacing one way of reproductive coercion by another, alternatively it could be seen as a proper first step to help people finding a way to combat the negative consequences of their traditions, in particular if consented by community members and community based organizations.

We should further note that interference with individual marital or reproductive choice on genetic grounds by stakeholders of a society is a universal phenomenon. Examples are the Orthodox Church in Cyprus and the role of the matchmaker in orthodox Jewish communities (see Henneman et al. 2016). Furthermore, almost globally, sexual relations between close relatives are forbidden by law, with legislations differing regarding the prohibited degree of relatedness. Justifications include eugenic aspects, explicitly so, for example, in a German Supreme Court ruling in 2008 (BVerfG 2008). Such reasoning was held unacceptable by the German Society of Human Genetics, arguing that this would endanger reproductive choice in general (Deutsche Gesellschaft für Humangenetik 2008).

A third paper recently published in this Journal (Rowe and Wright 2019) focusses on the potential resource implications of expanded universal carrier screening (EUCS). Although "maximising reproductive autonomy" is not questioned by them as the goal, the cost-effectiveness is the central issue. They discuss that increased reproductive autonomy is a difficult outcome to assess, and not often reported. This makes it difficult to provide evidence that investing in EUCS will be more beneficial than other healthcare interventions. In a publicly funded health care system, they argue, evidence is needed to compare EUCS to other health care expenditure and justify the use of limited health care resources.

Taken together, we feel that this Journal should accept that different ethical traditions exist, between and within different societies, and that a fair and open debate demands some degree of "cultural relativism". As editors we welcome debate on contentious issues. As countries and cultures differ, and develop over time, the ways in which community genetics programmes are implemented will also differ. An academic debate on the pros of cons of different strategies can help local or regional communities shape their opinion and support decision making on future policies. Community genetics is an area bearing ethical conflicts in many ways. This Journal takes pride in being a global forum for workers in this field. We think that ethically contentious issues need to be discussed openly.

Acknowledgements The authors are grateful to Angus Clarke, Cardiff, for helpful discussions.

\section{References}

Biesecker BB (2001) Goals of genetic counseling. Clin Genet 60:323330

Bittles AH (2019) Population structure and inherited genetic disorders in the Bedouin of the Negev. J Community Genet 25. First online July 25, 2019

BVerfG (2008) Beschluss des Zweiten Senats vom 26. Februar 2008-2 BvR 392/07 -, Rn. (1-128), http://www.bverfg.de/e/rs20080226 2bvr039207.html. Accessed 21 Oct 2019

De Wert GM, Dondorp WJ, Knoppers BM (2012) Preconception care and genetic risk: ethical issues. J Community Genet 3:221-228

Deutsche Gesellschaft für Humangenetik (2008) medgen 20:239

Henneman L, Borry P, Chokoshvili D, Cornel MC, van El CG, Forzano F, Hall A, Howard HC, Janssens S, Kayserili H, Lakeman P, Lucassen A, Metcalfe SA, Vidmar L, de Wert G, Dondorp WJ, Peterlin B (2016) Responsible implementation of expanded carrier screening. Eur J Hum Genet 24:e1-e12

Modell B (2019) Haemoglobin disorders - a point of entry for community genetics services in India? J Community Genet. First online December 06, 2019

Rogowski WH, Grosse SD, Schmidtke J, Marckmann G (2014) Criteria for fairly allocating scarce health-care resources to genetic tests: which matter most? Eur J Hum Genet 22:25-31

Rowe CA, Wright C (2019) Expanded universal carrier screening and its implementation within a publicly funded healthcare service. J community genet. First online December 11, 2019

Schmidtke J (1998) A Commentary on the NIH Consensus Development Statement 'Genetic Testing for Cystic Fibrosis'. Community Genet $1: 53-56$

Singer S, Davidovitch N, Fraiha YA, Freha NA (2019) Consanguinity and genetic diseases among the Bedouin population in the Negev. $\mathrm{J}$ Community Genet. https://doi.org/10.1007/s12687-019-00433-8

Sinha S, Seth T, Colah RB, Bittles AH (2019) Haemoglobinopathies in India: estimates of blood requirements and treatment costs for the decade 2017-2026. J Community Genet. First online February 12, 2019

Ten Kate LP, Al-Gazali L, Anand S, Bittles A, Cassiman JJ, Christianson A, Cornel MC, Hamamy H, Kääriäinen H, Kristoffersson U, Marais D, Penchaszadeh VB, Rahman P, Schmidtke J (2010) Community genetics. Its definition 2010. J Community Genet 1:19-22

Publisher's note Springer Nature remains neutral with regard to jurisdictional claims in published maps and institutional affiliations. 